Oceanography has started a new section entitled "The Future of Oceanography." This section allows young scientists (those who recently received or are about to receive their Ph.D.s) to introduce themselves and their research to the oceanographic community. Each scientist is given about a page (including one figure) to describe some facet of his/her Ph.D. work.

In order for a scientist to be considered, a TOS member must recommend him/her. If you are interested in nominating a young scientist, please send a letter to the editor or an associate editor with the name and present address of the nominee.

\title{
Fluorescence Efficiency of SuRface Seawater AS A FUNCTION OF EXCITATION AND EMISSION WAVELENGTH
}

\author{
by Sarah A. Green
}

$\mathrm{F}$ CENCE of natural waters has often been employed in attempts to quantify dissolved chromophores. However, it has not always been recognized that the intensity of fluorescence obtained from a given water sample depends on the fluorescence efficiency of the absorbing components as well as on the concentration of light-absorbing material present. Although fluorescence intensities have been compared for a variety of seawater samples (Willey and Atkinson, 1982: Hayase et al., 1988; Chen and Bada, 1989), there have been few measurements of the efficiency of emission in natural waters (Zepp and Schlotzhauer, 1981; Ferrari and Tassan, 1991). As one part of my Ph.D. work, I determined quantum efficiencies as a function of excitation wavelength for a series of surface-seawater samples.

Fluorescence quantum yield $(\phi)$ is defined as the ratio of emitted to absorbed photons. For any natural water, $\phi$ depends both on the types of chromophores present and on their relative concentrations. Yet, it is always independent of dilution factors. In contrast to a system containing only a single chromophore,

S.A. Green, Department of Chemistry, University of Texas, Austin. Texas 78712, USA: Ph.D. 1992. MIT/Woods Hole Oceanographic Institution (Advisors: N.V. Blough and F.M.M. Morel). in a mixture $\phi$ may be a function of excitation wavelength. Determination of $\phi$ requires accurate measurement of absorption coefficients and emission intensities over the UV-visible range. Because isolation techniques for organic carbon can change the distribution of chromophores in a sample, (Green, 1992) it is preferable to measure fluorescence on water that is unaltered except for removal of particles by filtration. However, this proves difficult in very clear oceanic waters where absorption of unconcentrated samples is below the detection limits of available instruments; fluorescence is still observable in these waters because of the inherently greater sensitivity of the technique.

In order to obtain a full spectral map of fluorescence efficiency, I combined absorption data with excitation/emission matrix plots that provide a map of fluorescence intensity over a range of wavelengths (Coble et al., 1990) (Fig. 1). Intensities at each excitation wavelength have been divided by the absorption at that wavelength; thus each point of this three-dimensional graph represents the fraction of photons emitted at a particular frequency (right axis) per photon absorbed at the corresponding excitation wavelength indicated on the left axis. Integration of the emission spectra gives a plot of quantum yield versus excitation wavelength (left); integration of excitation spectra gives the total emission obtained under broad-band light (equal intensity $260-470 \mathrm{~nm}$ ). A quinine sulfate solution $\left(\mathrm{OD}=0.1\right.$, in $1 \mathrm{~N} \mathrm{H}_{2} \mathrm{SO}_{4}$ ) was used to calibrate the fluorometer output to quantum yield.

Fluorescence intensity maxima of natural organic matter are generally observed at excitation and emission wavelengths of 345 and $445 \mathrm{~nm}$, respectively, with an additional band appearing for short-wavelength excitation $(\approx 300 \mathrm{~nm}$ ) (Coble et al., 1990). In contrast, Figure 1 shows that maximum fluorescence $e f$ ficiency is obtained for $395 \mathrm{~nm}$ excitation, with emission centered at $480 \mathrm{~nm}$. The decrease in efficiency for excitation below $350 \mathrm{~nm}$ demonstrates that, although light absorption increases nearly exponentially with shorter wavelengths, emission does not increase in proportion.

The shape of fluorescence efficiency plots was surprisingly consistent for surface waters collected in the Gulf of Mexico, Oyster Bay (Everglades National Park), the Amazon and Orinoco Rivers, and the Caribbean Sea, as well as for dissolved organic carbon (DOC) isolated from the Sargasso Sea at depths of 50$3,200 \mathrm{~m}$. In addition, the quantum efficiency of fluorescence at a reference excitation wavelength $\left(\lambda_{\mathrm{ex}}=355 \mathrm{~nm}\right)$ fell in a narrow range of $0.75-2 \%$ for all nat- 


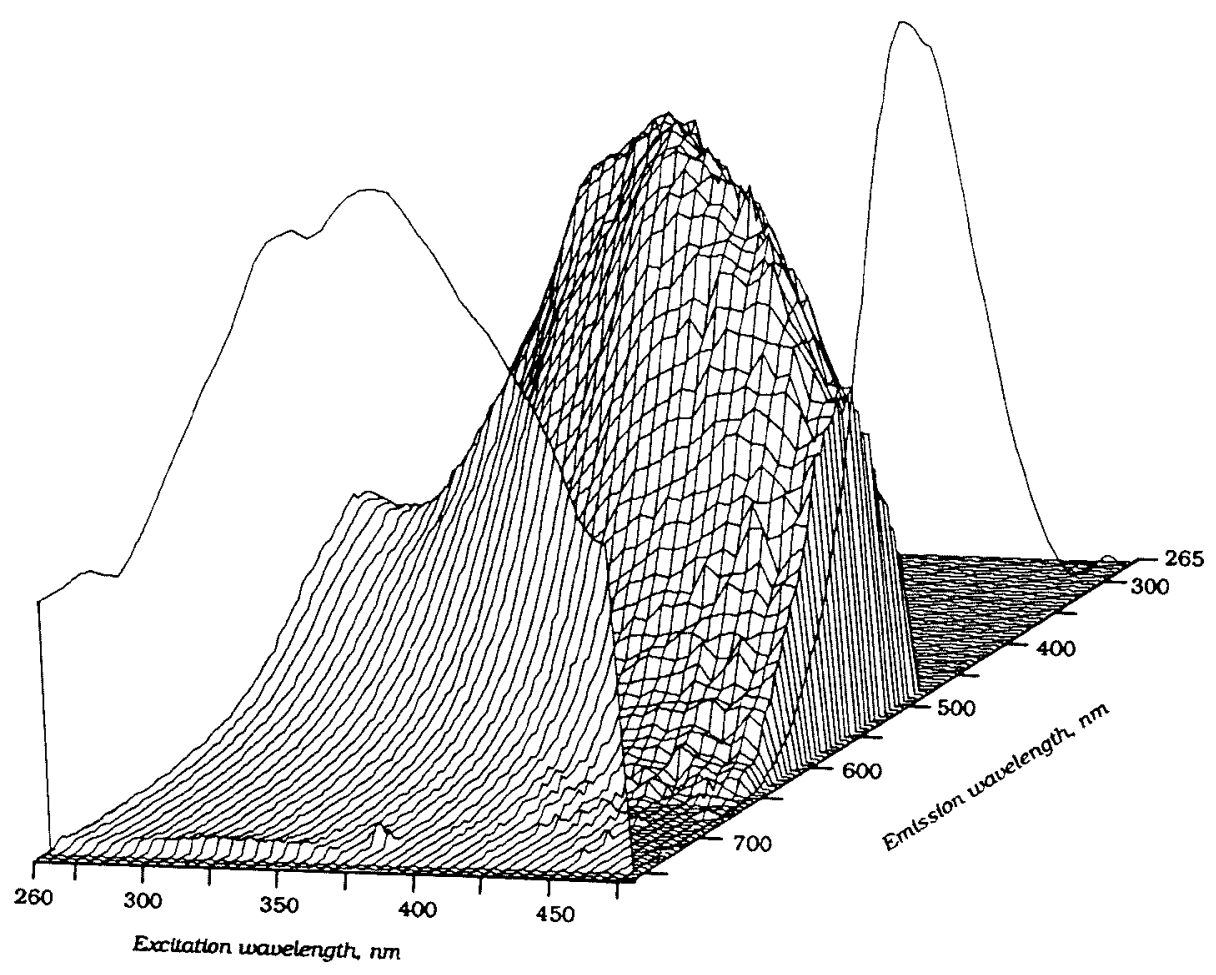

Fig. 1: Excitation and emission fluorescence efficiency plot of surface seawater from the Gulf of Mexico. The individual spectra projected onto the left (red) and right (blue) axes represent integrated fluorescence yield versus excitation and emission wavelength, respectively. Data were collected on an SLM-Aminco 500C fluorometer; 43 scans were concatenated to form this figure. Spectra have not been corrected; the effect of emission correction would be to uniformly augment intensities at the red edge of the emission axis. Diminished instrumental performance at $\lambda<310 \mathrm{~nm}$ decreases intensities in this region by an estimated 15\%. Raman scatter has been subtracted.

ural samples examined. This suggests that fluorescence, at defined excitation and emission points. is a reliable indicator of absorbing material and encourages current attempts to employ fluorescence detection for quantification of dissolved chromophores by remote sensing methods (Hoge and Swift, 1982, 1985; Bristow et al., 1985). In current work, fluorescence efficiency plots are being combined with the solar spectrum to predict the total emission spectrum of solarinduced fluorescence from surface waters of varying organic content (Vodacek, 1992). This information can then be employed to increase the accuracy of algorithms used in the estimation of phytoplankton polutions from satellite observations.

Three-dimensional fluorescence efficiency matrices provide essential information for the development of photon budgets for the oceans (Smith et al., with the assistance of N.V. Blough, and funding was provided by the Office of Naval Research under Contract No. N00014-89-J-1260.

\section{References}

Bristow, M.P.F.. D.H. Bundy. C.M. Edmonds and P.E. Ponto, 1985: Airborne fluorosensor survey of the Columbia and Snake Rivers: simultaneous measurements of chlorophyll. dissolved organics and optical attenuation. Int. J. Remote Sen., 6, 1707-1734.

Chen, R.F. and J.L. Bada, 1989: Seawater and porewater fluorescence in the Santa Barbara Basin. Geophys. Res. Lett., 16, 687-690.

Coble. PG.. S.A. Green, N.V. Blough and R.B. Gagosian. 1990: Characterization of dissolved organic matter in the Black Sea by fluorescence spectroscopy. Nature, 348 . $432-435$.

Ferrari, G.M. and S. Tassan, 1991: On the accuracy of determining light absorption by "yellow substance" through measurements of induced fluorescence. Limnol. Oceanogr., 36. 777-786.

Green, S.A. 1992: Applications of fluorescence spectroscopy to environmental chemistry. Ph.D. Thesis, Mass Institute of Teclnology, Woods Hole Oceanographic Institute Joint Program In Oceanography, $240 \mathrm{pp}$.

Hayase. K., Tsubota, H., Sunada, I., 1988: Vertical distribution of fluorescent organic matter in the North Pacific. Mar. Chem., 25, 373-381.

Hoge, F.E. and R.N. Swift. 1982: Deliniation of estuarine fronts in the German Bight using airborne laser-induced water Raman backscatter and fluorescence of water column constituents. Int. J. Remote Sens., 3, 475495

Hoge, F.E. and R.N. Swift, 1985: Airborne mapping of laser-induced fluorescence of chlorophyll $a$ and phycoerythrin in a Gulf Stream warm core ring. In: Mapping Strategies in Chemical Oceanography. A. Zirino, ed. The American Chemical Society, 353-372.

Smith, R.C., J. Marra, M.J. Perry, K.S. Baker, E. Swift. E. Buskey and D.A. Kiefer, 1989: Estimation of a photon budget for the upper ocean in the Sargasso Sea. Limnol. Oceanogr.. 34, 1673-1693.

Vodacek. A.. 1992: A model of solar-stimulated fluorescence of chromophoric dissolved organic matter. In: Autonomous Biooptical Ocean Observing Systems (ABOOS) Scientific Symposium, Monterey, CA.

Willey, J.D. and L.P. Atkinson, 1982: Natural fluorescence as a tracer for distinguishing between Piedmont and Coastal Plain River water in the nearshore waters of Georgia and North Carolina. Estuar. Coast. Shelf Sci., 14. 49-59.

Zepp, R.G. and P.F. Schlotzhauer, 1981: Comparison of photochemical behavior of various humic substances in water: III. Spectroscopic properties of humic substances. Chemosphere, 10, 479-486. 